\title{
The Chemistry of van de Moer Test for Cytisine
}

\section{Francisco Sánchez-Viesca* and Reina Gómez}

Organic Chemistry Department, Faculty of Chemistry, National Autonomous University of Mexico, Mexico City (CDMX), Mexico; e-mail: franviesca@yahoo.com

* Corresponding author

\begin{abstract}
Cytisine is an alkaloid with biological activity that is used as medication for smoking cessation treatment. It is a quinolizidine derivative, one ring being 2-pyridinone, and there is a third cycle, a disubstituted piperidine. Thus, the analytical chemistry of this compound is relevant. In this communication we provide the chemistry involved in the spot test for cytisine identification by means of ferric chloride/hydrogen peroxide. The electron flow, step by step, is given from the alkaloid to the final colored products. The sequence is based on the chemical properties of the substrate and reagents, disclosing the series of reactions occurring in this assay. The process is in accordance with the experimental results. We also give the mechanism of cytisine degradation, from a quinolizidine system to 6,8-dimethyl quinoline, which involves an interesting rearrangement.
\end{abstract}

\section{Introduction}

Cytisine, $\mathrm{C}_{11} \mathrm{H}_{14} \mathrm{~N}_{2} \mathrm{O}$, is a three ringed alkaloid, featuring a quinolizidine system that includes a 2-pyridinone moiety; the third ring is a disubstituted piperidine. The importance of this compound is due to its biological properties which help to stop smoking in about 25 days. This action was discovered in Eastern Europe, and afterwards cytisine was also used in Central Europe and recently in Canada and Australia, [1].

The alkaloid comes from Cytisus laburnum and it is found mainly in the seeds. The tree is also called Golden Rain (Acacia), and the leaves were used as false tobacco. In the

Received: March 18, 2021; Accepted: April 12, 2021

Keywords and phrases: cytisine, free radical chemistry, 2-pyridinone, quinolizidine, reactive intermediates, rearrangement, smoking cessation.

Copyright () 2021 Francisco Sánchez-Viesca and Reina Gómez. This is an open access article distributed under the Creative Commons Attribution License, which permits unrestricted use, distribution, and reproduction in any medium, provided the original work is properly cited. 
test under study cytisine reacts with ferric chloride and hydrogen peroxide giving a red colour that changes to blue. In this communication we provide the mechanism of the reactions that occur in this assay. This communication is a follow up of our studies on the chemistry of colour tests, [2-6].

\section{Antecedents}

The more relevant studies about cytisine, a quinolizidine alkaloid, Figure 1, are pointed out. Gray in Edinburgh made extracts containing cytisine and studied the physiological action on animals and man, [7, 8]. The alkaloid was isolated in Germany by Husemann and Marmé, [9]. After several steps and via the well crystallizing nitrate, cytisine was obtained as colorless radiant crystals. It has a strong alkaline reaction, neutralizes the strongest acids and can be sublimated between watch glasses.
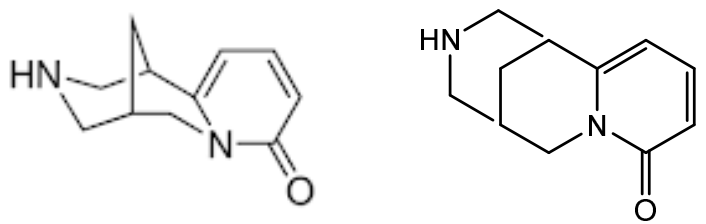

Figure 1. Cytisine structures.

Ewins established the constitution of two bases previously obtained by the action of hydriodic acid and phosphorus on cytisine at $225-230^{\circ} \mathrm{C}$. One of them afforded a third product by reduction with sodium in alcohol. These products were identified by synthesis and are related to 6,8-dimethyl quinoline, a nitrogen being lost as ammonia, [10]. This result is very interesting but it is misleading since the product comes from a rearrangement. The reaction mechanism of this degradation is provided in the 'Discussion'.

Other studies were made in Austria by Späth [11], and the structure elucidation was achieved in England by Ing, [12, 13]. The synthesis of cytisine was carried out by Bohlman and collaborators, [14]. The absolute configuration was studied in Japan [15], and the crystal structure was reported in England, [16]. There is other synthesis of cytisine, [17].

There are two recent patents for cytisine isolation, [18, 19]. This indicates the importance of the compound. The colour reaction for cytisine studied in this communication is due to J. van de Moer, who published it in the Netherlands, was reviewed in England, [20], and registered in the United States, [21]. Since the chemistry 
of this test has not been described, we provide the reaction course, step by step, in the next section.

\section{Discussion}

Let us see the reaction sites in cytisine, especially in the 2-pyridinone ring. Besides the tautomeric phenol structure, 2-hydroxypyridine, there are contributing dipolar structures. We consider that the 2-pyridinone ring contains two halves: one with an electron donor enamine, and the other having an electron withdrawing system, an $\alpha, \beta$ unsaturated carbonyl group. Polarization of these two groups indicates the pertinent reaction sites ( $\mathrm{C}-\mathrm{H}$ functionalization). This is confirmed experimentally by the bromination of 2-pyridinone [22], and recently by the halogenation of cytisine, [23, 24].

Thus, the colour reaction of cytisine with ferric chloride/hydrogen peroxide goes as follows, Figure 2.<smiles>[R]c1cccc(=O)n1[R]</smiles>

a<smiles></smiles>

b

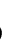<smiles>CC(C)(Cl)CC(=O)O</smiles><smiles>[R]C1=[N+]([O-])C(=O)C=CC1</smiles>

c

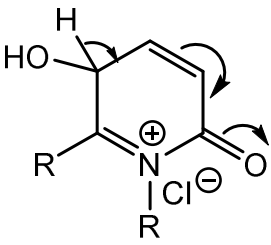

d<smiles>[R]c1c(O)ccc(O)[n+]1[O-]</smiles><smiles>[R]c1c(O[18O])ccc(O)[n+]1[O-]</smiles>

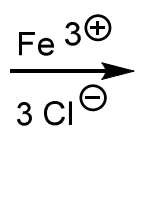

$\mathbf{f}$<smiles>[R]c1c(OC)ccc(O)[n+]1[O-]</smiles>

g<smiles>[R]C1=[N+]([O-])C(=O)C=CC1=O</smiles>

i

Figure 2. Reaction of cytisine at five position. 
Ferric chloride takes out one electron from C-5; besides the resulting free radical, ferrous chloride and the iminium chloride are formed, $\mathbf{a}, \mathbf{b}, \mathbf{c}$. The free radical at C-5 induces homolytic fission of hydrogen peroxide. Ferric chloride can also activate or decompose hydrogen peroxide, $[25,26]$. Combination of the resulting free radicals gives a hydroxy group at C-5, d. The hydrogen at C-5 is $\gamma$-to the $\alpha, \beta$-unsaturated system, thus prototropy occurs, affording a quinol, 2,5-dihydroxyiminium chloride, e. The acidic phenol groups are electron rich substrates for reaction with ferric chloride, f, g. So, oxygen radicals can be formed and a p-quinone is obtained, $\mathbf{h}, \mathbf{i}$.

Reaction at C-3 can be explained by the electrodotic [27] properties of the conjugated enamine, providing a negative charge $\alpha$ to carbonyl, Figure 3.

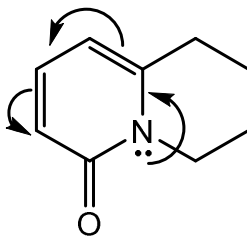

a

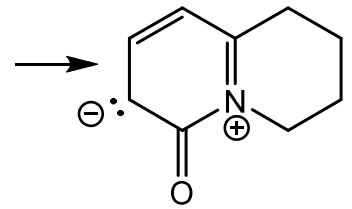

b<smiles>O=C1[C@H](Cl)C=CC2=[N+]1CCCC2</smiles>

c

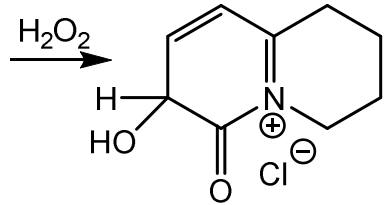

d

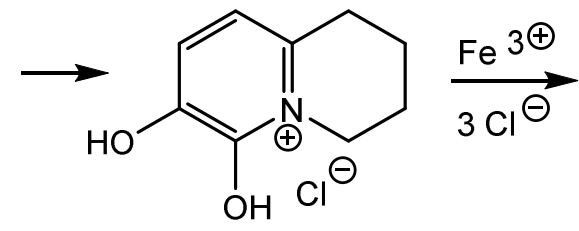

$\mathbf{e}$

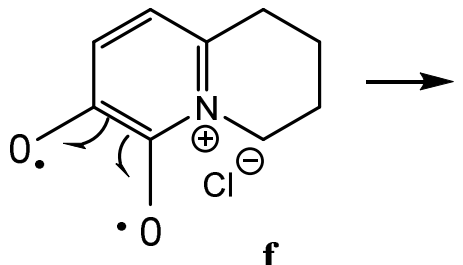

f

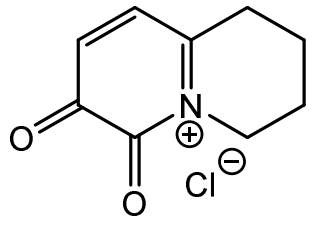

g

Figure 3. Reaction of cytisine at 3 position.

Reaction with ferric chloride affords the free electron that reacts with hydrogen peroxide, $\mathbf{b}, \mathbf{c}, \mathbf{d}$. The transient alcohol isomerizes to an ortho diphenol, $\mathbf{e}$ The electron shift (carbon acid) is favored besides by aromatization. Further oxidation via free radicals at oxygen gives an ortho quinone, $\mathbf{f}, \mathbf{g}$. This is the key to the red colour produced in the assay, since ortho quinones are red; for instance, o-benzoquinone [28], 1,2naphtoquinone [29], o-toluquinone [30], and others.

Finally, the change from red to blue is explained by formation of a quinhydrone-type complex, that is, a hydrogen bonded complex with a network $\mathrm{C}=\mathrm{O}---\mathrm{HO}$ hydrogen bonds, [31]. The $0.5 \%$ solution of ferric chloride and $0.05 \%$ hydrogen peroxide solution 
are insufficient for complete quinone formation. If quinol remains, the corresponding green- blue or blue quinhydrone is formed.

The other point of interest is the degradation of cytisine to 6,8-dimethylquinoline since this involves a rearrangement from a quinolizidine structure, with a nitrogen common to both rings, to quinoline, with the nitrogen only in one ring, Figure 4.<smiles>C[C@@H]1C[C@@H]2CC1Cn1c2cccc1=O</smiles>

$\mathbf{a}$

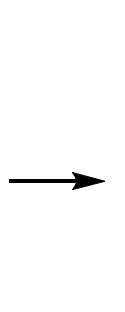

$\mathrm{H}_{2}$ c<smiles>C=C1CC(=C)C2=NC(=O)C=CC2C1</smiles><smiles></smiles><smiles>C=C1CCc2cccc(=O)n2CC1</smiles><smiles>C=C1C=C2C(=O)C=CC(=O)N2C(=O)C1</smiles>

d<smiles>CC1=CC2C=CC(=O)N=C2C(C)=C1</smiles>

g<smiles>Cc1cc(C)c2[nH]c(=O)ccc2c1</smiles>

$\mathbf{h}$

Figure 4. Cytisine degradation by means of hydriodic acid.

First occurs the acid/base reaction of hydriodic acid with the piperidine nitrogen; the salt is broken by heat, a $\mathrm{CH}_{2}$ cation is formed and an exocyclic methylene results by 
neutralization, a, b, c. The primary amine reacts similarly, ammonia is released, and a second exocyclic methylene is formed, $\mathbf{d}$.

Polarization of the enamine in the 2-pyridone ring and high temperature produces ring opening and 1-3 migration via $180^{\circ}$ rotation of the C6-R bond and a new ring closure, e, f. Acid catalyzed isomerization of the methylene groups gives two methyl groups and two double bonds, g. Protonation at nitrogen induces aromatization of ring B, h.

Finally, reduction of the carbonyl group by hydriodic acid affords 6,8dimethylquinoline. The phosphorus reacts with the iodine formed in the oxidation of iodide ions.

\section{Conclusion}

The chemistry of the test for cytisine due to J. van de Moer has been cleared up. It involves ferric chloride promoted free radical reactions which in combination with hydrogen peroxide produce quinols, a p-quinone and an o-quinone. The last one brings about the red colour observed in the test.

The colour change to blue comes from a quinhydrone-type complex. If there is incomplete oxidation, quinol remains and the hydrogen bonded complex is formed.

Finally, the reaction mechanism of cytisine degradation is provided. It involves ammonia elimination from the piperidine ring, exocyclic methylene groups and a 1-3migration via ring opening and ring closure at different reaction site. Prototropy and reduction affords the final product, 6,8-dimethylquinoline.

\section{References}

[1] V. Tzankova and N. Danchev, Cytisine-from ethomedical use to the development as a natural alternative for smoking cessation, Biotechnology \& Biotechnological Equipment 21(2) (2007), 151-160. https://doi.org/10.1080/13102818.2007.10817436

[2] F. Sánchez-Viesca and R. Gómez, On the mechanism of uric acid oxidation with lead dioxide and with alkaline hydrogen peroxide, Indian J. Adv. Chem. Sci. 8(3) (2020), 7880. https://doi.org/10.22607/IJACS.2020.803001

[3] F. Sánchez-Viesca and R. Gómez, The mechanism of nitric acid degradation of the C-glycoside aloin to aloe emodin, Am. J. Chem. 10(1) (2020), 1-5.

https://doi.org/10.5923/j.chemistry.20201001.01 
[4] F. Sánchez-Viesca and R. Gómez, Formation mechanism of the colored compounds derived from Eserine (Physostigmine), World J. Org. Chem. 8(1) (2020), 1-4. https://doi.org/10.12691/wjoc-8-1-1

[5] F. Sánchez-Viesca and R. Gómez, The chemistry of Lindo and Fages colour tests, Earthline J. Chem. Sci. 5(1) (2021), 119-125. https://doi.org/10.34198/ejcs.5121.119125

[6] F. Sánchez-Viesca and R. Gómez, The chemistry of Marchand's test for strychnine identification, Magna Scientia Adv. Res \& Rev. 01(01) (2020), 018-022. https://doi.org/10.30574/msarr.2020.1.1.0020

[7] Th. S. Gray, An inquiry into the chemistry and properties of the Cytisus laburnum, Edinburgh Med. Journ. 7(10) (1862), 908-919. PMCID: PMC5315927

[8] Th. S. Gray, An inquiry into the chemistry and properties of the Cytisus laburnum. II, Edinburgh Med. Journ. 7(11) (1862), 1025-1037. PMCID: PMC5315964

[9] A. Husemann and W. Marmé, Vorläufige Mittheilung über Cytisin und Laburnin, zwei neue Pflanzenbasen in Cytisus Laburnum, Zeitschrift für Chemie 8(1) (1865), 161-162. https://hdl.handle.net/2027/ucl.63481648

[10] A. J. Ewins, The constitution of Cytisine, the alkaloid of Cytisus laburnum, synthesis of $\alpha$ - and $\beta$-cytosolidine, J. Chem. Soc., Trans. (London) 103 (1913), 97-104. https://doi.org/10.1039/CT9130300097

[11] E. Späth, Zur Konstitution des Cytisins, Monatsh. Chem. 40 (1920), 15-33. https://doi.org/10.1007/BF01524434

[12] H. R. Ing, Cytisine, Part I, J. Chem. Soc. (London) (1931), 2195-2203. https://doi.org/10.1039/JR9310002195

[13] H. R. Ing, Cytisine, Part II, J. Chem. Soc. (London) (1932), 2778-2780. https://doi.org/10.1039/jr9320002778

[14] F. Bohlmann, A. English, N. Ottawa, H. Sander and W. Weise, Synthese des Cytisins, Angew. Chem. 67(22) (1955), 708. https://doi.org/10.1002/ange.19550672214

[15] S. Okuda, K. Tsuda and H. Kataoka, Absolute configuration of (-) anagyrine and of the related C15 lupine alkaloids, Chem. \& Ind. (London) (1961), 1751.

[16] P. Mascagni, M. Christodoulou, W. A. Gibbons, K. Asres, J. D. Phillipson, N. Nicolai and S. Mangani, Solution and crystal structure of cytisine, a quinolizidine alkaloid, $J$. Chem. Soc. Perkin Trans. 2 (1987), 1159-1165. https://doi.org/10.1039/p29870001159

[17] D. Yohannes, K. Procko, L. A. Lebel, C. B. Fox and B. T. O’Neill, Deconstucting cytisine: the synthesis of (+/-) cytosine, Bioorg. Med. Chem Lett. 18 (2008), 2316-2319. https://doi.org/10.1016/j.bmcl.2008.02.078 
[18] Method of isolating cytisine from biomaterial, European Patent Office, EP 2292629 A1. Date: 09.03.2011

[19] Method for isolation of cytisine, WO 2019144204 Publication Number, WO/2019/144204. Publication date: 01.08.2019

[20] J. van de Moer, A delicate reaction for cytisine, The Analyst (London) 16(3) (1891), 5758, (from Ned. Tydschr v. Pharmacie, February, 1891). https://doi.org/10.1039/an8911600057

[21] A. I. Cohn, Tests and Reagents, p. 208, New York: J. Wiley \& Sons, 1903.

[22] O. S. Tee and M. Paventi, Kinetics and mechanism of bromination of 2-pyridinone and related derivatives in aqueous solution. J. Am. Chem. Soc. 104(15) (1982), 4142-4146. https://doi.org/10.1021/ja00379a016

[23] P. Imming, P. Klaperski, M. T. Stubbs, G. Seitz and D. Gündisch, Synthesis and evaluation of halogenated cytisine derivatives and of bioisosteric theory thiocytisine as potent and selective nAChR ligands, Eur. J. Med. Chem. 36(4) (2001), 375-388. https://doi.org/10.1016/S0223-5234(01)01222-3

[24] R. W. Fitch, Y. Kaneko, P. Klaperski, J. W. Daly, G. Seitz and D. Gündisch, Halogenated and isosteric cytisine derivatives with increased affinity and functional activity at nicotinic acetylcholine receptors, Bioorg. Med. Chem. Lett. 15(4) (2005), 1221-1224. https://doi.org/10.1016/j.bmcl.2004.11.073

[25] H. Sugimoto and D. T. Sawyer, Ferric chloride induced activation of hydrogen peroxide, J. Org. Chem. 50(10) (1985), 1784-1786. https://doi.org/10.1021/jo00210a053

[26] B. Bilach, G.R. Gross and J. K. Koob, Catalytic decomposition of hydrogen peroxide, Publication 91847 (2016), Flinn Scientific, Inc. Online, access with the title. Last login, March 16, 2021.

[27] W. F. Luder and S. Zuffanti, The Electronic Theory of Acids and Bases, $2^{\text {nd }}$ ed., pp. 7172, New York: Dover, 1961.

[28] H. Beyer, Organic Chemistry, Frankfurt/Main and Zürich: H. Deutsch, 1963, p. 402.

[29] I. Heilbron and H. M. Bunbury, Dictionary of Organic Compounds, vol. 3, p. 566, London: Spottiswoode, 1953.

[30] I. Heilbron and H. M. Bunbury, Dictionary of Organic Compounds, vol. 4, p. 525, London: Spottiswoode, 1953.

[31] P. W. G. Smith and A. R. Tatchel, Aromatic Chemistry, Chapter VII, pp. 144-175, Oxford, UK: Pergamon, 1969. https://doi.org/10.1016/B978-0-08-012948-8.50010-3 